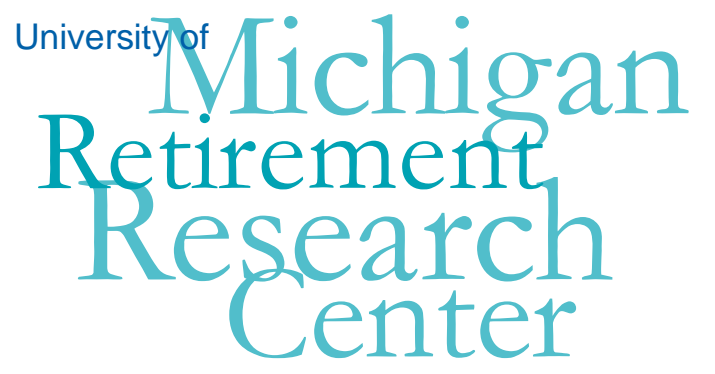

Working Paper

WP 2011-254

\title{
Consumption and Differential Mortality
}

\author{
Michael Hurd and Susann Rohwedder
}

\begin{tabular}{|l|l|}
\hline $\mathrm{M}$ & $\mathrm{R}$ \\
\hline $\mathrm{R}$ & $\mathrm{C}$ \\
\hline
\end{tabular}

Project \#: UM11-17 



\title{
Consumption and Differential Mortality
}

\author{
Michael Hurd \\ RAND and NBER \\ Susann Rohwedder \\ RAND \\ September 2011 \\ Michigan Retirement Research Center \\ University of Michigan \\ P.O. Box 1248 \\ Ann Arbor, MI 48104 \\ http://www.mrrc.isr.umich.edu/
}

(734) 615-0422

\section{Acknowledgements}

This work was supported by a grant from the Social Security Administration through the Michigan Retirement Research Center (Grant\# RRC08098401-03-00). The findings and conclusions expressed are solely those of the author and do not represent the views of the Social Security Administration, any agency of the Federal government, or the Michigan Retirement Research Center.

\section{Regents of the University of Michigan}

Julia Donovan Darrow, Ann Arbor; Laurence B. Deitch, Bingham Farms; Denise Ilitch, Bingham Farms; Olivia P. Maynard, Goodrich; Andrea Fischer Newman, Ann Arbor; Andrew C. Richner, Grosse Pointe Park; S. Martin Taylor, Gross Pointe Farms; Katherine E. White, Ann Arbor; Mary Sue Coleman, ex officio 


\title{
Consumption and Differential Mortality
}

\begin{abstract}
It is well-established that differential mortality according to wealth or income introduces bias into age profiles of these variables when estimated on cross-sectional or synthetic cohort data. However, little is known about whether this association is also found with consumption, and if so, how strong this association is. In this paper we use panel data on total household spending from the Health and Retirement Study (HRS) and its supplemental study, the Consumption and Activities Mail Survey (CAMS), to estimate differences in consumption by survival status to the next survey wave. We quantify the bias in age profiles of consumption that results from differential mortality when estimating the age profiles on cross-sectional data or on synthetic cohort data. We find that the bias is smaller than that found for wealth or income.
\end{abstract}

\section{Authors’ Acknowledgements}

This work was supported by a grant from the Social Security Administration through the Michigan Retirement Research Center (Grant UM11-17). The findings and conclusions expressed are solely those of the author and do not represent the views of the Social Security Administration, any agency of the Federal government, or the Michigan Retirement Research Center. Joanna Carroll provided excellent programming assistance. 


\section{Introduction}

The most direct indicator of economic well-being is consumption, and it is of substantial scientific and policy interest to understand how consumption varies over the latter part of the life cycle. The main data source in the United States for understanding levels and patterns of spending over the life-cycle has been the Consumer Expenditure Survey (CEX,) which collects cross-sectional data on consumption (see for example Aguiar and Hurst, 2008). However, the variation in the level of consumption with age in the CEX may not yield life-cycle paths. ${ }^{1}$ First, because of the differing lifetime resources of different cohorts, some component of the variation with age will be the result of those differing resources. Second, mortality may differ with consumption levels: If so, the cross-sectional pattern will partially reflect the systematic selection by age. While synthetic cohort studies can correct for differing life-time resources across cohorts, they cannot correct for such mortality differences and so they also will not yield life-cycle paths of spending.

There are good reasons to believe that mortality risk is associated with consumption levels. It is well established that mortality is associated with measures of socio-economic status such as income, wealth, and education and that those with greater income or wealth have higher consumption. ${ }^{2}$ However, we know of no studies that have related mortality to consumption itself, despite the fact that according to the leading theory of the intertemporal allocation of economic resources, consumption is the best measure of both economic resources and economic well-being. If consumption and mortality are linked, studies of life-cycle consumption paths based on an observed relationship between age and consumption will misestimate those paths unless differential mortality is accounted for. How strong this

\footnotetext{
${ }^{1}$ The PSID has been used in a number of studies, but because its measures are incomplete it cannot be used to study either levels or budget shares if those shares vary either with the level of spending or with age.

${ }^{2}$ Examples of studies of differential mortality are Attanasio and Hoynes (2000), or Attanasio and Emmerson (2003) for estimates by wealth; Duleep (1986 and 1989), Deaton and Paxson (2004), and Bommier et al. (2003) for estimates by income and income inequality, Marmot (1999) for estimates by occupational status, Feldman et al. (1989) and Lleras-Muney (2005) for estimates by education, and Adams et al. (2003) and Deaton and Paxson (2001) for estimates by broader measures of socioeconomic status.
} 
bias may be is an empirical matter, but an implication of the correlation between consumption levels and mortality is that true panel data are required to estimate life-cycle consumption paths. For example, both cross-section data and synthetic panels may show increasing consumption with age even though all surviving individuals decrease consumption with age.

Theoretical considerations do not clearly predict how, or the extent to which, differential mortality might be associated with household spending. ${ }^{3}$ Consider a framework in which a latent fitness factor varies from person to person. Those who are more fit will have better health and better SES both in levels and in life-cycle improvements (when measured by income or wealth). In addition, higher SES may lead to better use of resources to preserve or improve health, which will further increase the advantage of the more fit. And even among a latent fitness class, those who fortuitously had better health outcomes will have earnings and wealth above the average for the fitness class.

Each of these mechanisms might lead to the observed correlation between SES and health. And because consumption increases with income and wealth, we would expect a positive correlation between income (and wealth) and survival. However, when we combine this model of health and economic status with a life-cycle model of consumption, the clear prediction of a positive correlation disappears. In the life-cycle model, high mortality risk induces high spending. While the latent health model would predict that those with higher resources will survive longer, the life-cycle model would predict that those with worse health and hence higher mortality risk will consume a greater fraction of their resources. Depending on the relative magnitudes of these effects, higher mortality in crosssectional samples could be associated with either higher or lower levels of consumption. An additional complicating factor that is not accounted for in these models is that high health care spending is associated with health shocks, which increase mortality risk. Whether these health shocks lead to

\footnotetext{
${ }^{3}$ We do not address the issue of causality with respect to any association between consumption and differential mortality, nor the causal flows from SES to health or from health to SES, as such analyses are beyond the scope of this study.
} 
higher total spending (as opposed to a higher proportion of out-of-pocket spending on health care) is an empirical question that we will investigate.

To quantify the association between differential mortality and consumption, we estimated consumption by age, stratifying further by whether the respondent or spouse (if applicable) died by the next survey wave. We attribute the difference in consumption levels by survivors and those households where the respondent or spouse died to differential mortality. We compare age profiles of consumption based on cross-sectional data and on panel data in CAMS and assess whether our estimates of the biases related to differential mortality fully account for the differences.

\section{Data}

The data for this study come from the Health and Retirement Study (HRS), a multipurpose, longitudinal household survey that provides rich data representing the U.S. population over the age of 50. The HRS sample comprises approximately 20,000 persons and 13,000 households. Since its inception in 1992, the HRS has surveyed age-eligible respondents and their spouses every two years (even-numbered years).

In 2001, the HRS added a supplemental survey eliciting details of household spending, the Consumption and Activities Mail Survey (CAMS). The CAMS is collected every two years (odd-numbered years) in the year between the core interviews. The CAMS sample consists of some 4,000 randomly selected HRS households, which provide information on some 38 categories of household spending, designed to measure total household spending over the preceding 12 months. The first wave of CAMS was conducted in October 2001, with subsequent waves following every two years. These spending data can be linked to the rich background information that respondents provide in the HRS core interviews. Rates of item nonresponse are very low (mostly single-digit), and CAMS spending totals 
aggregate closely to those in the CEX (Hurd and Rohwedder, 2009). In this study, we used five waves of CAMS, spanning the period from 2001 through 2009.

\section{Results}

Pooling the data for the 2000, 2002, and 2004 HRS, we first compared the wealth of individuals who survived to the next survey wave to that of those who died by the time of the next data collection. This comparison allowed us to demonstrate the strength of the association between mortality and wealth in the HRS data. We then conducted the same exercise with respect to household spending, that is, we compared spending of those individuals who survived to the next survey wave to those who died. Data were stratified by age group and marital status.

\section{Differential Mortality and Wealth}

Singles, Age 75-79: Among the 2,307 individuals followed across the 2000, 2002, and 2004 waves, 226 individuals died (mortality rate 9.8 percent), and 2,081 survived. The mean per-household wealth in the wave prior to death for those who died was $\$ 126,455$, compared with $\$ 223,001$ among survivors. The mean overall wealth was $\$ 213,543$. The wealth of those who died was 59.2 percent of the average (Table 1).

Couples, Age 75-79: Among the 4,330 persons who were members of a couple, during the 2000, 2002, and 2004 waves, 301 died and 4,029 survived (mortality rate 7.0 percent, reflecting the previously identified lower mortality rate among married persons). The mean per-household wealth among couples where one spouse died between waves was $\$ 380,847$. In comparison, when both members of a couple survived, the mean wealth per couple was $\$ 483,054$. The wealth of couples where one spouse 
died was 80 percent of the average wealth (Table 2). Comparing the wealth of single survivors $(\$ 223,001 ;$ Table 1$)$ to that of widows or widowers (members of a couple in which one spouse died) $(\$ 380,847)$, shows that widowhood, or the process of becoming a widow, increases the wealth, crosssectionally, of the group of singles whom they are joining.

The Impact of Age on Wealth Ratios: Pooling all three waves and stratifying into 5-year age increments, we then examined the effect of age group on the ratio of deceased/survivor mean and median wealth for individuals. The ratio was always less than one (indicating that the deceased had less wealth than survivors in all age groups. With the exception of those in the 70-74-year old group and those 85 and over, the deceased had no more than 68 percent of the mean wealth of the survivors in the two years prior to death (Figure 1). Comparing the median wealth between the deceased and survivors, i.e., the wealth of typical individuals, revealed larger disparities: With the exception of those 90 and over, the wealth of persons who died in the previous year was less than 51 percent that of survivors in every age group. In the youngest age group for which data were collected, those 55 to 59 , the wealth of the deceased was less than one percent that of survivors (Figure 2).

Repeating the same analysis for couples showed that with increasing age, the ratio of deceased to survivor mean wealth tended to increase, reaching a maximum of 90 percent in the 80 to 84 -year old group before falling slightly in the older age groups (Figure 3). The ratios of deceased to survivor median wealth were much lower and did not trend upward with increasing age (Figure 4).

\section{Summary}

Analysis of the HRS data for the 2000, 2002, and 2004 waves showed that among single persons, the mean wealth of those who deceased in the prior two years was 81 percent of that of survivors. The 
median wealth of those who deceased, which reflects the actual wealth distribution of individuals, was only 45 percent of that of survivors.

Among couples, the mean wealth of those who deceased was 66 percent of that of survivors. The disparity in median wealth was nearly identical, 65 percent.

\section{Differential Mortality and Consumption}

To examine the association between mortality and consumption (spending), we analyzed five waves of data from the HRS-CAMS, spanning 2001 to 2009.

Single Persons, Age 65 to 74. Among single persons, age 65 to 74, who survived from 2005 to 2007, 2005 per-household spending was $\$ 21,785$, declining slightly to $\$ 21,572$ in 2007 (Table 3). In comparison, spending was lower in 2005 among those who died between 2005 and 2007: \$20,308. Among those who were added to the cohort, spending was higher: $\$ 29,247$ : This latter group largely comprises individuals recently widowed. Thus, although mean cross-sectional spending increased with age from 2005 to 2007 (from $\$ 21,605$ to $\$ 22,889$ ), spending actually decreased among the cohort of single persons followed from 2005 to 2007 (true panel).

The data for all four waves were then combined. As with the 2005 to 2007 transition, mean spending by survivors was higher than for those who deceased $(\$ 23,407$ vs. $\$ 22,148)$. Similarly, spending by survivors declined slightly from one wave to the next $(\$ 23,407$ vs. $\$ 22,210)$ (Table 4). Persons who joined the cohort through widowhood spent more: $\$ 25,029$. However, cross-sectional spending declined from $\$ 23,656$ in the younger group to $\$ 22,669$ in the older group.

Single Persons, Age 75 and Over. Among older adults, those 75 and over, mean spending by survivors was actually lower than spending by those who deceased in the preceding cycle $(\$ 22,479$ vs. 
$\$ 24,499)($ Table 5). Spending also declined with time $(\$ 22,479$ vs. $\$ 20,695)$. Those who joined the cohort, again principally the widowed, spent $\$ 23,949$ more than the survivors who were already members of the cohort, but less than those who died. Thus in this age group, cross-sectional spending declined with age (from $\$ 22,674$ to $\$ 21,249$ ).

Couples, Age 65 to 74. Among couples in the 65-to-74 year old age group, per-household spending was greater among survivors than among those who deceased in the previous cycle $(\$ 39,754$ vs. $\$ 35$, 689) (Table 6). Spending among survivors declined with time $(\$ 39,754$ vs. $\$ 37,787)$. Spending by individuals who joined the cohort slightly exceeded spending by survivors who were already members of the cohort $(\$ 39,772$ vs. $\$ 39,754)$. Cross-sectional spending declined by age $(\$ 39,881$ vs. $\$ 37,950)$.

Couples, Age 75 and Over. Among couples 75 and over, mean per-household spending was substantially higher among survivors than among those who deceased during the previous wave $(\$ 36,451$ vs. $\$ 30,939)$ (Table 7$)$. Spending declined among survivors over time (from $\$ 36,451$ to $\$ 34,579)$. Spending by those who joined the cohort was $\$ 33,753$ higher than that of those deceased but lower than surviving members of the cohort. Cross-sectional spending declined with age $(\$ 36,218$ vs. $\$ 34,513)$.

Summary. Among single individuals age 65 to 74 , mean spending prior to death was approximately 95 percent of spending by survivors, whereas among singles 75 and over, spending prior to death exceeded that of spending by survivors by approximately 9 percent. Among couples age 65 to 74 , mean spending prior to the death of one member of the couple was approximately 90 percent of that of spending by surviving couples, whereas among those 75 and over, spending prior to the death of one member of the couple was approximately 85 percent of that of surviving couples. Thus, wealth showed greater effects of differential mortality than did spending. 


\section{Spending to Wealth Ratios}

To assess what might account for the seemingly small effect of dying on spending, we compared spending as a proportion of wealth across our demographic groups. As Table 8 shows, across all age and marital status groups, spending to wealth ratios were higher among those who became deceased than among survivors. Comparing this ratio between survivors and the deceased, the largest disparity was seen among singles 75 and over. Thus the dying spend a greater proportion of their wealth than do those who survive, and this proportion is greater for singles than for married persons. However this analysis could not pinpoint what components of spending are higher prior to death. One common assumption is that it is spending on health care services.

To test this assumption, we analyzed the proportion of total spending accounted for by health care (exclusive of insurance premiums) among our sample. Those 75 and over, both singles and couples, spent the highest proportion on health care. Expressing the difference between health care spending by those who died and spending by survivors as a ratio, singles and couples 75 and over had the highest health care spending as a proportion of total expenditures, followed by couples from 65 to 74 (Table 9). The budget share for health care for singles 75 and over who died was 50 percent greater than for those who survived.

\section{Implications for Age Profiles of Spending}

To obtain unbiased life-cycle spending paths, one needs to follow couples and singles over time; that is, panel data on specific individuals are required to estimate how spending changes with age. Because of differential mortality with respect to spending, estimated age-profiles based on crosssectional data will yield biased life cycle paths. The bias is expected to be particularly large among singles. Following singles cross-sectionally at older ages from one wave to the next, the composition changes due to poorer singles being removed from the sample (they tend to die earlier than other singles), while at the same time the sample of singles is replenished each wave with relatively rich singles who have recently been widowed. The latter tend to be much more affluent than those 
widowed some time ago - again a result of differential mortality. These new widows have higher spending. Furthermore, different cohorts have different economic resources due to differences in lifetime earnings and saving. These differences introduce further bias into age profiles of consumption estimated on cross-sectional data, compared to the true life-cycle paths of spending.

When panel data are not available, researchers often construct synthetic panels from the time series of cross-sections (see for example Gourinchas and Parker, 2002). Consider 70 to 75 year-olds in cross-section in 2001. When observed in cross-section in 2006, that cohort will be 76 to 81 . The ratio of their spending in 2006 to their spending in 2001 will give the cohort change in spending: Although not the same people, they represent the cohort population in both cross-sections. Thus, the comparison holds cohort lifetime resources constant. However, differential mortality will cause this ratio to differ from the ratio that would be obtained from panel data, for the same reasons that we discussed for cross-sectional data.

To investigate the magnitude of the difference between cross-sectional and synthetic panel age-profiles and age-profiles based on panel data, we used panel data from CAMS to construct age-profiles based on the three methods: panel data, synthetic panel data, and cross-sectional data. We converted all spending to 2003 dollars. For cross-sectional data, we simply pooled data by age and marital status across five CAMS waves. For true panel data, we identified all two-wave panel observations and calculated rates of change in spending. For synthetic cohorts, we made the following definitions and calculations:

1. We defined nine birth cohorts of five birth years each: 1947-1943 (cohort 1), 1942-1938 (cohort 2) and so forth.

2. We assessed spending and average age of each cohort over the five waves and from them calculated rates of change in spending over a limited range of ages. We illustrate this calculation in Table 10.

The interpretation for this cohort's spending is that as the cohort aged from about 69 to 71 years, mean spending increased by 1.8 percent. With further aging from 71 to 73 , spending decreased by about 13 percent. Spending continued to decline as the cohort aged further. From these rates of change, we can construct synthetic panel spending paths. But composition is not held constant for the synthetic panel as it would be in a true panel. Because of differential mortality, the cohort loses its 
poorest members over time, causing spending to decline less than it would otherwise. Furthermore, over time, the proportion of single-person households is increasing and these households spend less on average than multi-person households. This shift causes the spending path to decline more rapidly than it would if the proportion of couples was not decreasing.

To generate synthetic panel life-cycle spending paths, we average the two-year changes in spending by age. Then we normalize to spending of 100 percent at age 66 and apply the two-year changes to generate synthetic panel life-cycle trajectories of spending. We show these trajectories in Figure 5 (a)-(f) along with the cross-sectional age profiles and the true panel profiles.

Figure 5 (a) and (b) show spending paths of all households, whether single persons or couples. The panel path shows how spending will evolve, taking into account the increasing proportion of single to married households. This path accounts for differential mortality and for differing cohort resources. The synthetic panel also controls for differing cohort resources but not for differential mortality.

The cross-sectional age-profile of mean spending differs substantially from those of the true panel and from the synthetic panel: For example, at age 86, spending is about 75 percent of the spending of 66 year-olds in the cross-sectional panel, whereas it is about 50 percent in the case of the true panel and synthetic panel. Were one to aim to estimate a life-cycle spending path from crosssectional data, the rate of decline would be just half of the true value.

For median spending, the results are qualitatively similar, but the differences are much smaller. Even so, the cross-sectional age profile is flatter than the panel profiles.

Figure 5 (c) shows the predicted mean spending paths of couples. In the case of the true panel, the paths are conditional on survival of both spouses; thus they represent life-cycle paths. Because of the small samples of the oldest participants, the results are not reliable past the age of about 89 . The true panel shows that if both spouses survive to 86 , spending will decline to about 50 percent of initial spending. The synthetic panel indicates a smaller decline because of differential mortality; although the magnitude of this difference is not great, it nevertheless exerts some effect. The cross-sectional age profile is very different from the true panel profile; thus it would give a misleading impression of the trajectory of mean spending. The differences in the medians (Figure 5 (d)) are small.

The results for single persons are shown in Figure 5 (e) and (f). The sample is large enough to reliably estimate the differences by age, except for the highest age. Especially for mean spending, the cross-sectional trajectory shows almost flat spending until age 93, whereas, the true panel path declines 
sharply, reaching just 40 percent of initial spending at age 92 . Thus, the cross-sectional trajectory predicts that spending will be twice as great at age 92 as would be predicted by the true panel. The synthetic panel tracks the true panel fairly closely, although it predicts higher spending at most ages. The medians (Figure 5(f)) show a similar pattern but with smaller differences.

\section{Summary and Conclusions}

The simplest life-cycle model predicts that wealth will decline as individuals and couples age during their retirement years. Measuring that decline is an important goal from both a scientific and a policy perspective. However, that measurement must overcome several difficulties. As a cohort ages, its average wealth evolves differently from the wealth of an individual or a household in that cohort. Because on average the less wealthy die sooner than the more wealthy, average cohort wealth will increase with age. Because couples are much wealthier than single persons, a new widow will add above-average wealth to the existing pool of widows, also causing wealth per single person to increase, and wealth per household (single persons and couples together) to increase. Both of these effects will flatten a declining age profile wealth path and could even cause the profile in cross-section data to increase.

If successive cohorts are wealthier at retirement due to greater lifetime wealth, the age profile of wealth in cross-section data will be tilted downward, offsetting some or all of the biases due to differential mortality and widowing. Thus, the overall effect on the age profile in cross-section data is ambiguous.

These are some of the problems found in estimating life-cycle spending paths, but additional difficulties are evident. According to the life-cycle model, spending adjusts for mortality risk. Thus, those most at risk of dying (and who subsequently will die at higher rates) will adjust their spending upward, causing a positive correlation between spending and mortality. In addition, as a practical matter, spending just prior to death for health care expenses is likely to be elevated increasing the correlation between mortality and spending. For these reasons, the relationship between the age profile of consumption as found in cross-section data will differ from the life-cycle profile, and even the sign of the difference cannot be specified a priori.

Synthetic panels can control for differences in cohort economic resources, but they still have the other drawbacks associated with cross-section data. Accordingly it should not be expected that they can be used to estimate life-cycle paths of consumption. 
We have found that there is a negative relationship between mortality and consumption in three of the four examples we studied: couples 65 to 74, couples 75 or older and single persons 65-74. But even when there is a negative relationship, it is much weaker than the negative relationship between mortality and wealth. One explanation is high health care spending prior to death: indeed the fraction of total spending devoted to health care was substantially higher in three of the four examples.

We compared age profiles in spending based on cross-section data, on synthetic cohort data and on panel data. The panel age profiles indicate more steeply declining spending with age than the synthetic panel age profiles, but the differences are small compared with the differences between the panel age profiles and the cross-section age profiles. We summarize those differences in the following table extracted from Figures 5 (c) - 5(f). It shows in the first three rows spending at age 84, conditional on spending of 100 percent at age 66. Spending in panel is always lower than spending in synthetic panel, as would be expected from considerations of differential mortality. It is very much lower than spending in cross-section. The lines "rates of spending change" show the average annual rate of spending change: for example, couples would have to change spending by $-1.61 \%$ per year to reach the level of 74.8 in the 18 years between age 66 and age 84 . The last lines show the deviation in that annual rate from the panel rate. The average deviation (averaged across the four deviations) for cross-section is $2.0 \%$ and it is $0.7 \%$ for synthetic panel.

Spending at age 84 and annual rates of spending change from age 66 to 84

\begin{tabular}{lrrrr}
\hline & \multicolumn{2}{c}{ couples } & \multicolumn{2}{c}{ singles } \\
& mean & median & mean & median \\
\cline { 2 - 5 } $\begin{array}{l}\text { Spending at 84 } \\
\text { cross-section }\end{array}$ & 74.8 & 77.3 & 91.3 & 78.9 \\
$\quad$ synthetic & 58.0 & 83.8 & 54.1 & 63.4 \\
$\quad$ panel & 49.7 & 70.9 & 50.7 & 55.8 \\
$\quad$ Rate of spending change & & & & \\
$\quad$ cross-section & -1.61 & -1.43 & -0.51 & -1.32 \\
$\quad$ synthetic & -3.03 & -0.98 & -3.41 & -2.53 \\
$\quad \begin{array}{l}\text { panel } \\
\text { Deviation in rate from panel }\end{array}$ & -3.88 & -1.91 & -3.77 & -3.24 \\
$\quad$ cross-section & & & & \\
$\quad$ synthetic & 2.27 & 0.48 & 3.27 & 1.92 \\
$\quad$ panel & 0.86 & 0.93 & 0.36 & 0.71 \\
& -- & -- & -- & -- \\
\hline
\end{tabular}

We conclude that while differential mortality with respect to spending is not nearly as strong as it is with respect to wealth, it does contribute to the large deviations in age profiles between panel and cross- 
section and between panel and synthetic panel. The differences between panel and cross-section are so large that the cross-section age profiles cannot be used to study life-cycle paths of spending. However, we tentatively conclude that synthetic panels can be used to approximate life-cycle paths 


\section{References}

Adams, P., M. Hurd, D. McFadden, A. Merrill and T. Ribeiro. 2003. "Healthy, Wealthy, and Wise? Tests for Direct Causal Paths between Health and Socioeconomic Status." Journal of Econometrics, 112:3-56.

Aguiar, M. and E. Hurst, 2008, "Deconstructing Lifecycle Expenditure," Michigan Retirement Research Center Working Paper WP 2008-173, January.

Attanasio, O. and C. Emmerson. 2003. "Differential Mortality in the UK." Journal of the European Economic Association, 1(4):821-850.

Attanasio, O. and H. Hoynes. 2000. "Differential Mortality and Wealth Accumulation." Journal of Human Resources, 35(1).

Bommier, A., T. Magnac, B. Rapoport and M. Roger. 2006. "Droit a la Retraite et Mortalite Differentielle." [Pension Entitlements and Differential Mortality] Économie et Prévision 168 :1-16.

Deaton A. and C. Paxson. 2001. "Mortality, education, income, and inequality among American cohorts." in Themes in the Economics of aging, edited D. Wise, Chicago University Press for NBER.

Deaton A. and C. Paxson. 2004. "Mortality, Income, and Income Inequality over Time in Britain and the US." in Perspectives in the Economics of Aging, edited by D. Wise. Chicago: University of Chicago Press.

Duleep, H. 1989. “Measuring socioeconomic mortality differentials over time." Demography, 26:345351.

Duleep H. 1986. "Measuring the Effect of Income on Adult Mortality Using Longitudinal Administrative Records Data." Journal of Human Resources, 21(2).

Feldman J., D. Makuc, J. Kleinman and J. Cornoni-Huntley. 1989. "National trends in educational differences in mortality." American Journal of Epidemiology, 129.

Gourinchas, Pierre-Olivier and Jonathan Parker (2002), "Consumption over the Life Cycle," Econometrica, January, 70, 1, 47-89.

Hurd, M. D. and S. Rohwedder. 2009. "Methodological Innovations in Collecting Spending Data: The HRS Consumption and Activities Mail Survey." Fiscal Studies 30(3/4):435-459.

Lleras-Muney, A. 2005. "The Relationship between Education and Adult Mortality in the United States." Review of Economic Studies 72:189-221.

Marmot M. 1999. "Multi-Level Approaches to Understanding Social Determinants." in Social Epidemiology, edited by L. Berkman and I. Kawachi. Oxford: Oxford University Press. 
Tables

Table 1. Wealth Disparities among Singles (Age 75-79) Who Became Deceased and Those Who Survived in the HRS 2000, 2002, and 2004 HRS cohorts

\begin{tabular}{lrrrr}
\hline & Died & Survived & Total & Ratio, died to total \% \\
\hline $\mathrm{N}$ & 226 & 2,081 & 2,307 & 9.8 \\
Wealth & 126,455 & 223,001 & 213,543 & 59.2 \\
\hline
\end{tabular}

Table 2. Wealth Disparities among Couples (Age 75-79) Who Became Deceased and Those Who Survived in the HRS 2000, 2002, and 2004 HRS cohorts

\begin{tabular}{lrrrr}
\hline & Died & Survived & Total & Ratio, died to total \% \\
\hline $\mathrm{N}$ & 301 & 4,029 & 4,330 & 7.0 \\
Wealth & 380,847 & 483,054 & 475,949 & 80.0 \\
\hline
\end{tabular}

Table 3. Spending Among Singles 65 to 74, 2005-2007

\begin{tabular}{lrr}
\hline & & 2005 \\
\hline Survived & 21,785 & 21,572 \\
Died & 20,308 & \\
Other non-response in 2007 & 20,219 & \\
Added in 2007 & & 29,247 \\
Total & 21,605 & 22,889 \\
\hline
\end{tabular}


Table 4. Mean Spending over the Average of Four Cycles among Singles, 65 to 74

\begin{tabular}{lrr}
\hline & Base wave & Following wave \\
\hline Survived & 23,407 & 22,210 \\
Died & 22,148 & \\
Other non-response in following wave & 25,549 & \\
Added in following wave & & 25,029 \\
Total & 23,656 & 22,669 \\
\hline
\end{tabular}

Table 5. Mean Spending over the Average of Four Cycles among Singles 75 and Over

\begin{tabular}{lrr}
\hline & Base wave & Following wave \\
\hline Survived & 22,479 & 20,695 \\
Died & 24,499 & \\
Other non-response in following wave & 22,052 & \\
Added in following wave & & 23,949 \\
Total & 22,674 & 21,249 \\
\hline
\end{tabular}

Table 6. Mean Spending over the Average of Four Cycles among Couples 65-74

\begin{tabular}{lrr}
\hline & Base wave & Following wave \\
\hline Survived & 39,754 & 37,787 \\
Died & 35,689 & \\
Other non-response in following wave & 42,311 & \\
Added in following wave & & 39,772 \\
Total & 39,881 & 37,950 \\
\hline
\end{tabular}

Table 7. Mean Spending over the Average of Four Cycles among Couples 75 and Over

\begin{tabular}{lrr}
\hline & Base wave & Following wave \\
\hline Survived & 36,451 & 34,579 \\
Died & 30,939 & \\
Other non-response in following wave & 37,891 & \\
Added in following wave & & 33,753 \\
Total & 36,218 & 34,513 \\
\hline
\end{tabular}


Table 8. Spending to Wealth Ratios (\%)

\begin{tabular}{lcccr}
\hline & Singles & \multicolumn{3}{c}{ Couples } \\
\hline & $65-74$ & $75+$ & $65-74$ & $75+$ \\
\cline { 2 - 5 } Survived & 10.6 & 9.6 & 6.8 & 6.7 \\
Died & 11.9 & 14.2 & 9.9 & 8.9 \\
Ratio: died to & & & & 1.33 \\
survived & 1.12 & 1.48 & 1.46 & 1.33 \\
\hline
\end{tabular}

Table 9. Percent of Total Spending for Health Care (Excluding Insurance)

\begin{tabular}{lrrrr}
\hline & Singles & \multicolumn{3}{c}{ Couples } \\
\hline & $65-74$ & $75+$ & $65-74$ & $75+$ \\
\cline { 2 - 5 } Survived & 7.3 & 9.9 & 7.2 & 8.2 \\
Died & 6.4 & 15.2 & 10.6 & 17.5 \\
Ratio & 0.88 & 1.54 & 1.47 & 2.13 \\
\hline
\end{tabular}


Table 10. Age and Spending of Birth Cohort 1928-1932

\begin{tabular}{lrrrrr}
\hline year observed & 2001 & 2003 & 2005 & 2007 & 2009 \\
\hline minimum age & 67 & 69 & 71 & 73 & 75 \\
mean age & 69 & 71 & 73 & 75 & 77 \\
maximum age & 72 & 74 & 76 & 78 & 80 \\
mean spending & 35,389 & 36,014 & 31,386 & 29,889 & 26,790 \\
median spending & 27,452 & 28,429 & 25,015 & 24,457 & 21,865 \\
\% change in spending & & & & & \\
$\quad$ mean & & 1.8 & -12.8 & -4.8 & -10.4 \\
$\quad$ median & & 3.6 & -12.0 & -2.2 & -10.6 \\
$N$ & 585 & 504 & 497 & 483 & 446 \\
\hline
\end{tabular}




\section{Figures}

Figure 1. Mean wealth of deceased singles relative to wealth of survivors (\%) by age group

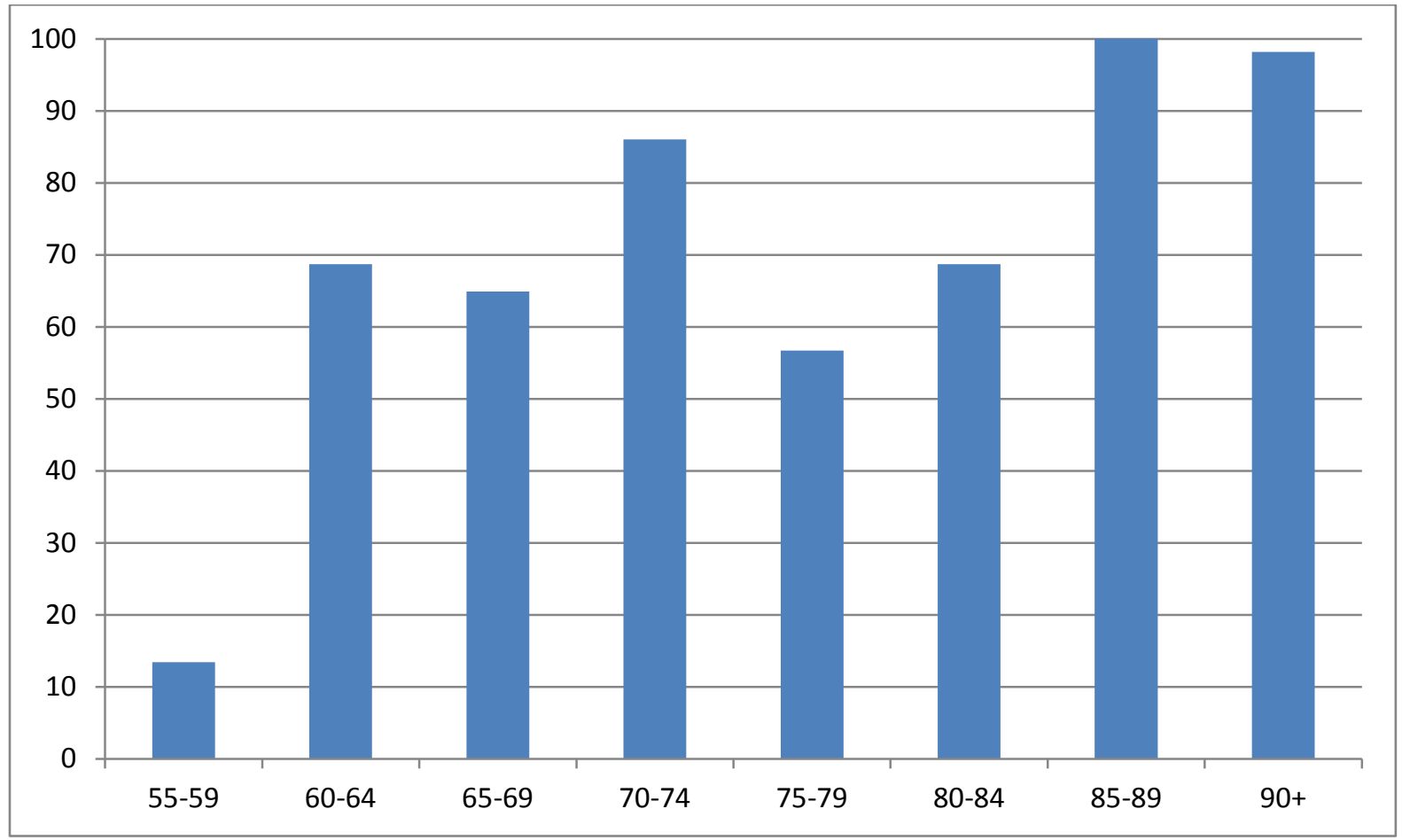


Figure 2. Median wealth of deceased singles relative to wealth of survivors (\%) by age group

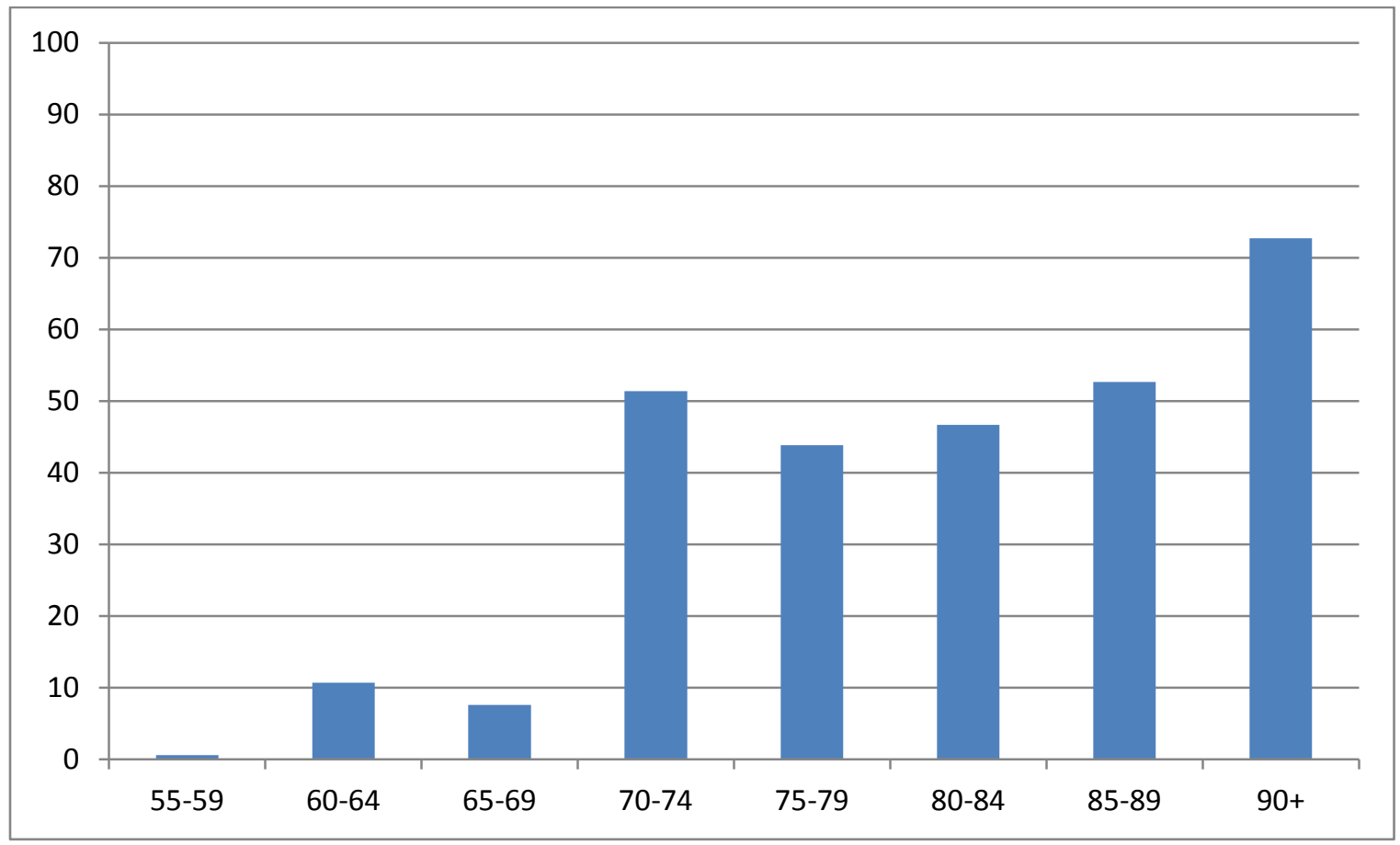


Figure 3. Mean wealth of couples with a deceased member relative to wealth of survivors (\%) by age group.

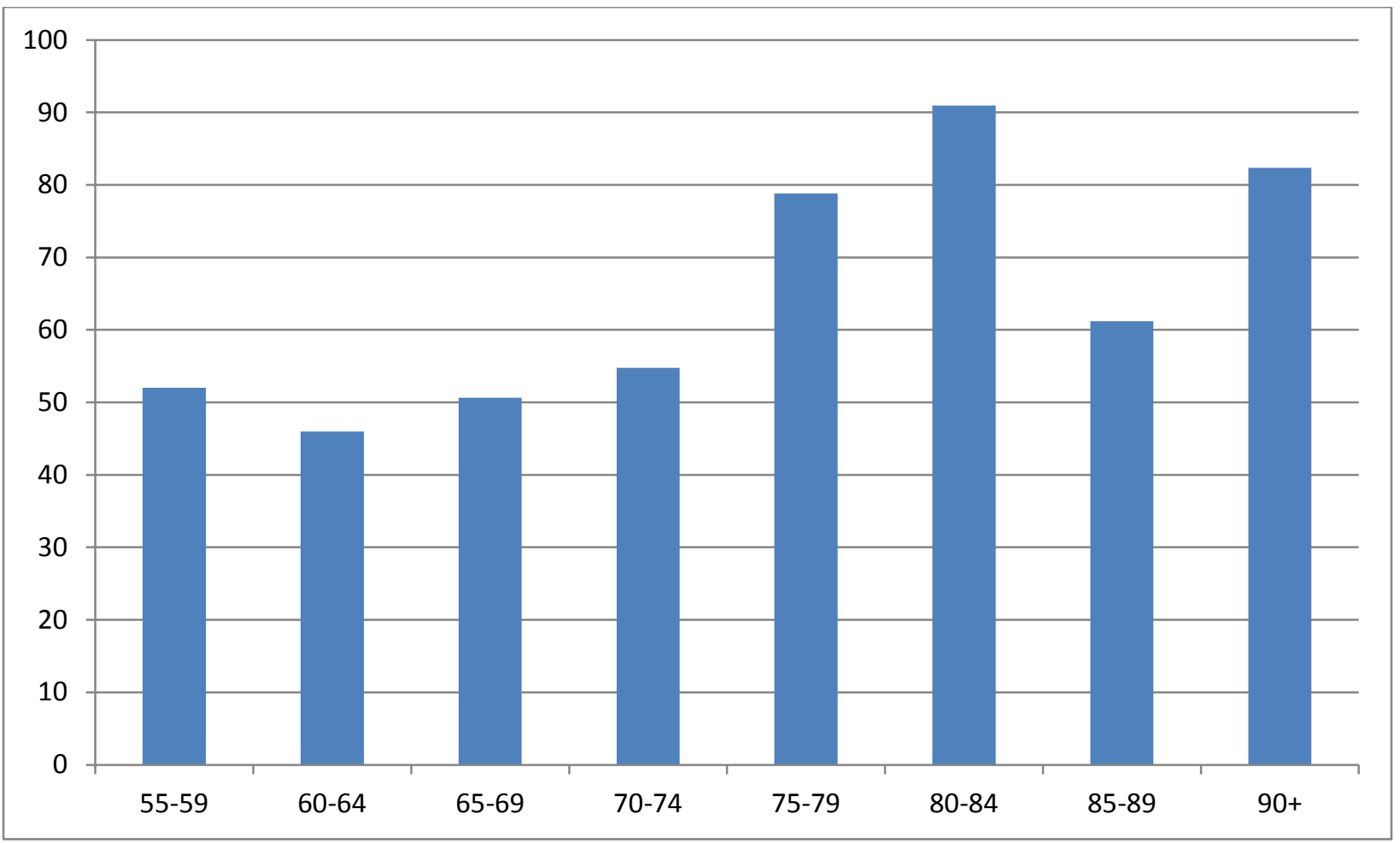


Figure 4. Median wealth of couples with one deceased member relative to wealth of survivors (\%).

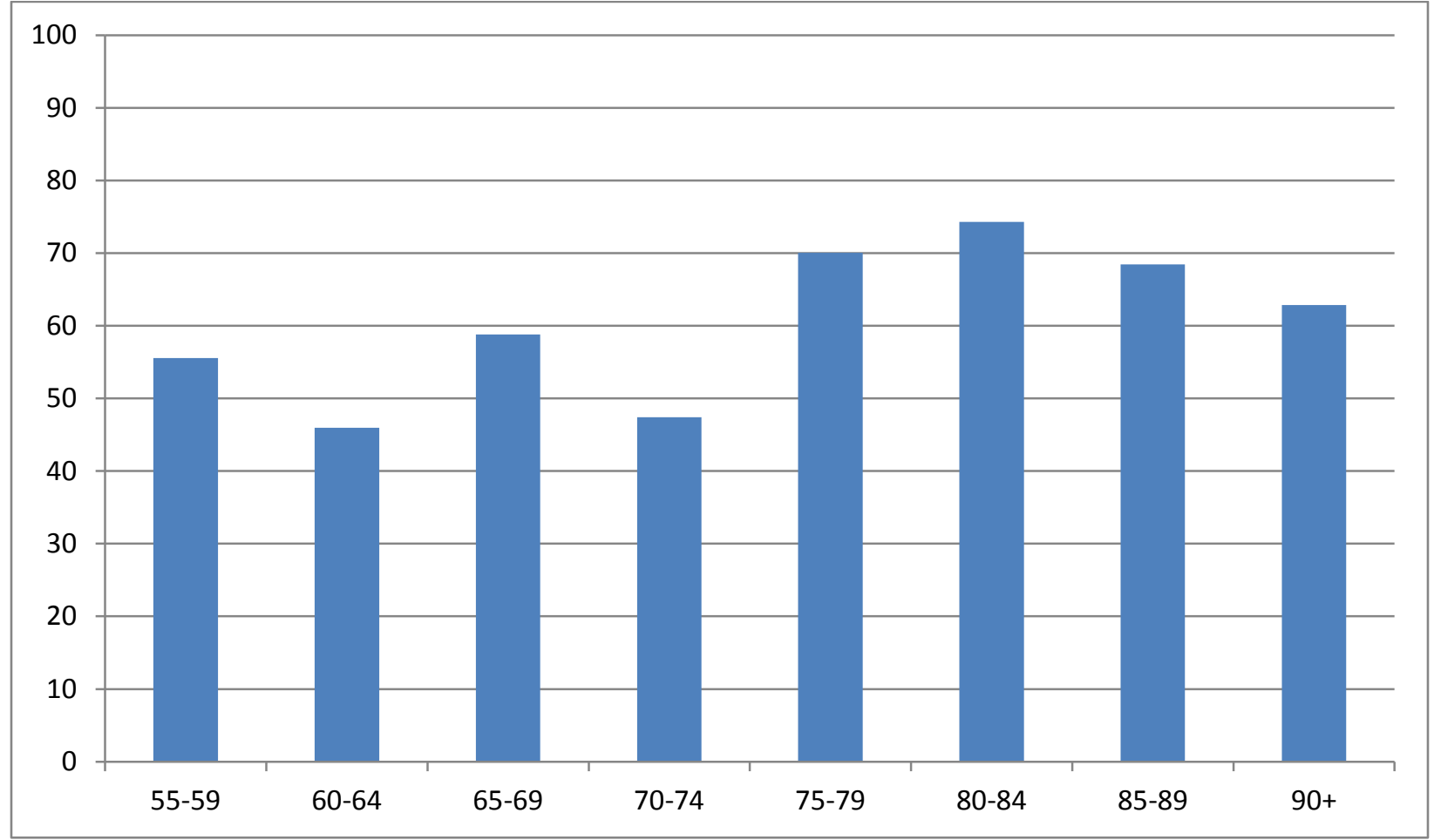


Figure 5 (a) Mean spending paths for both couples and singles

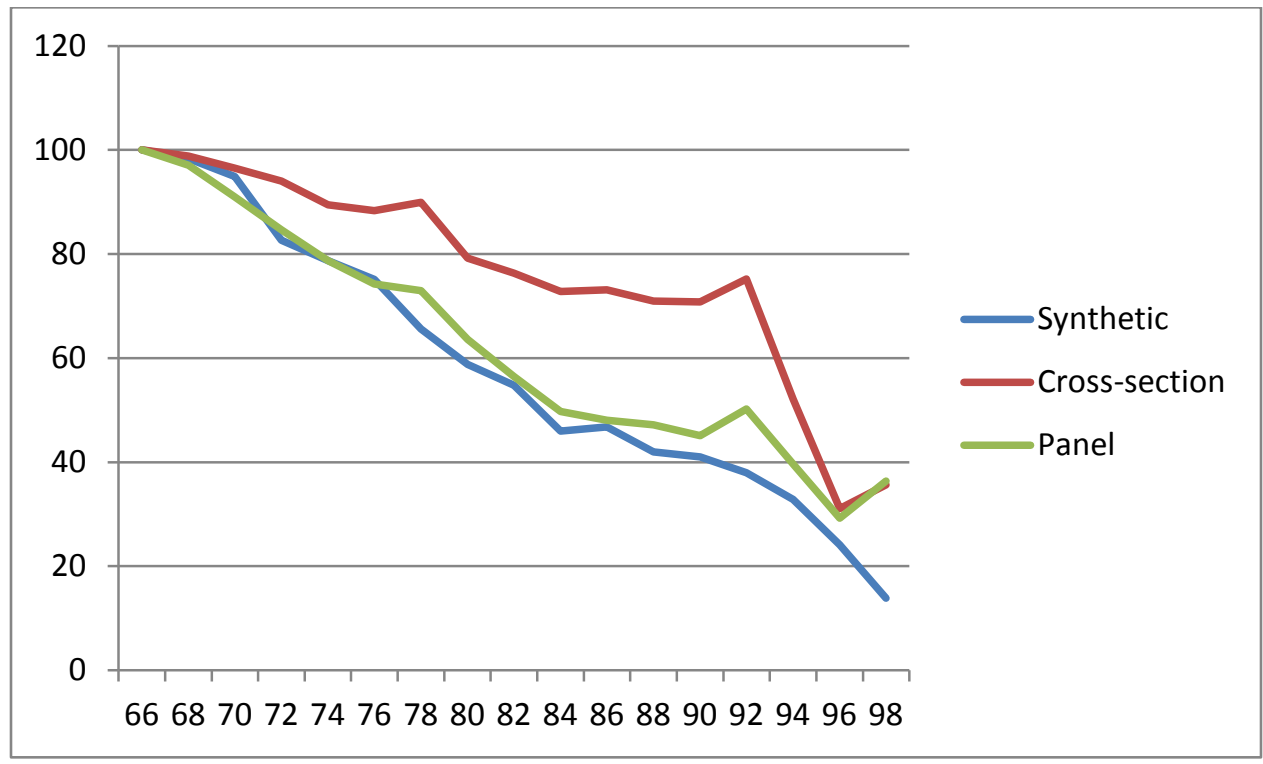

Figure 5 (b) Median spending paths for both couples and singles

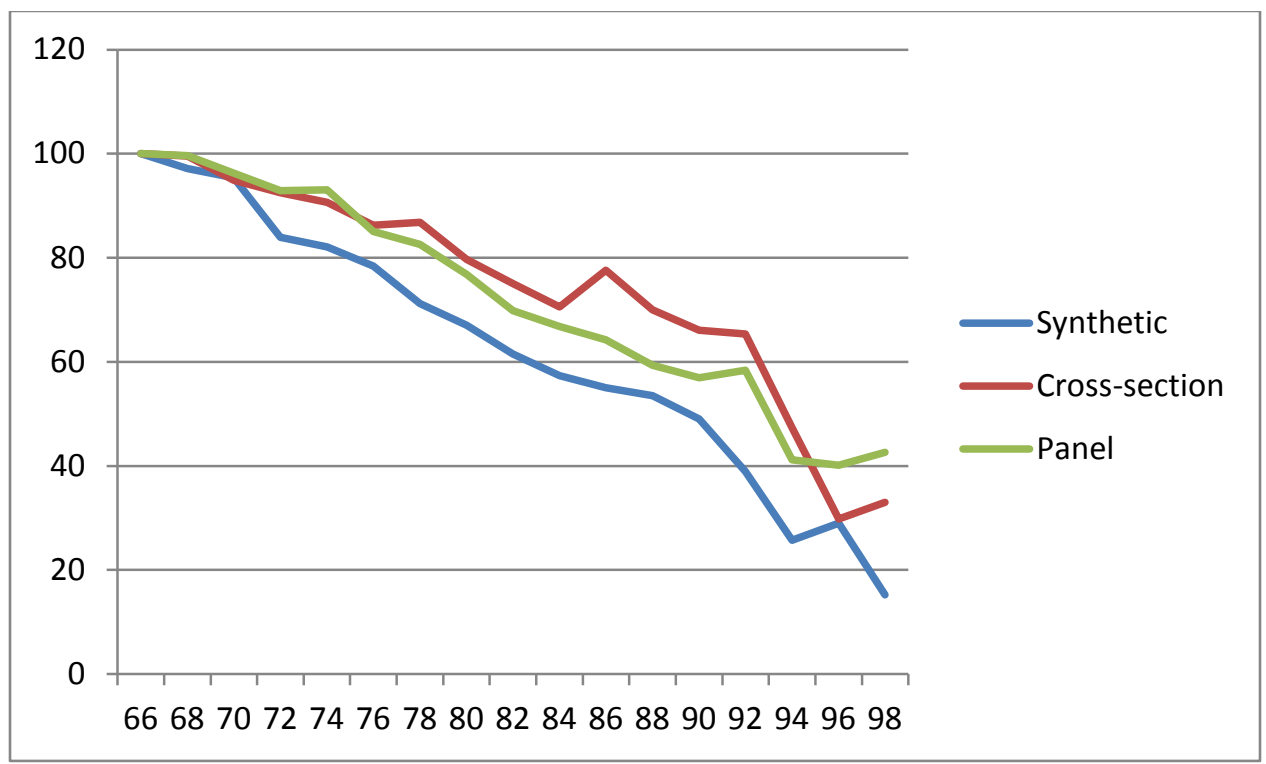


Figure 5 (c) Mean spending paths for couples

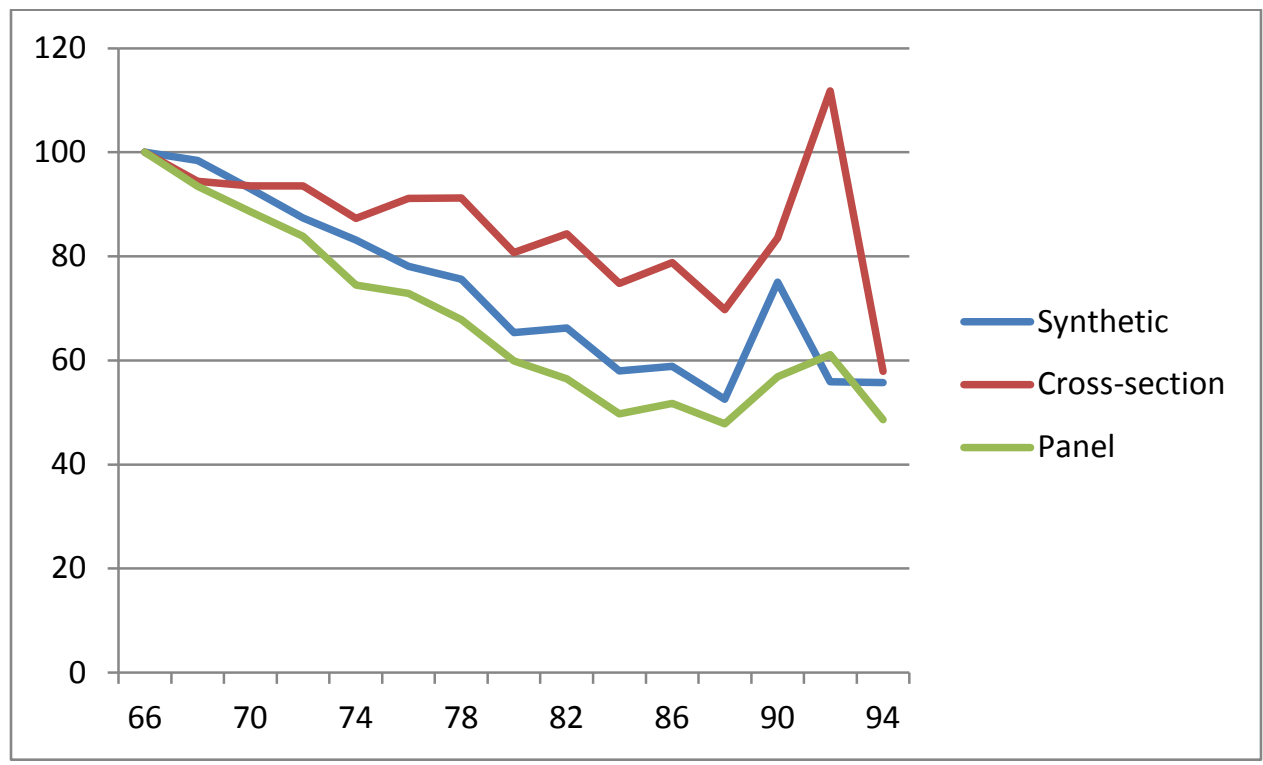

Figure 5 (d) Median spending paths for couples

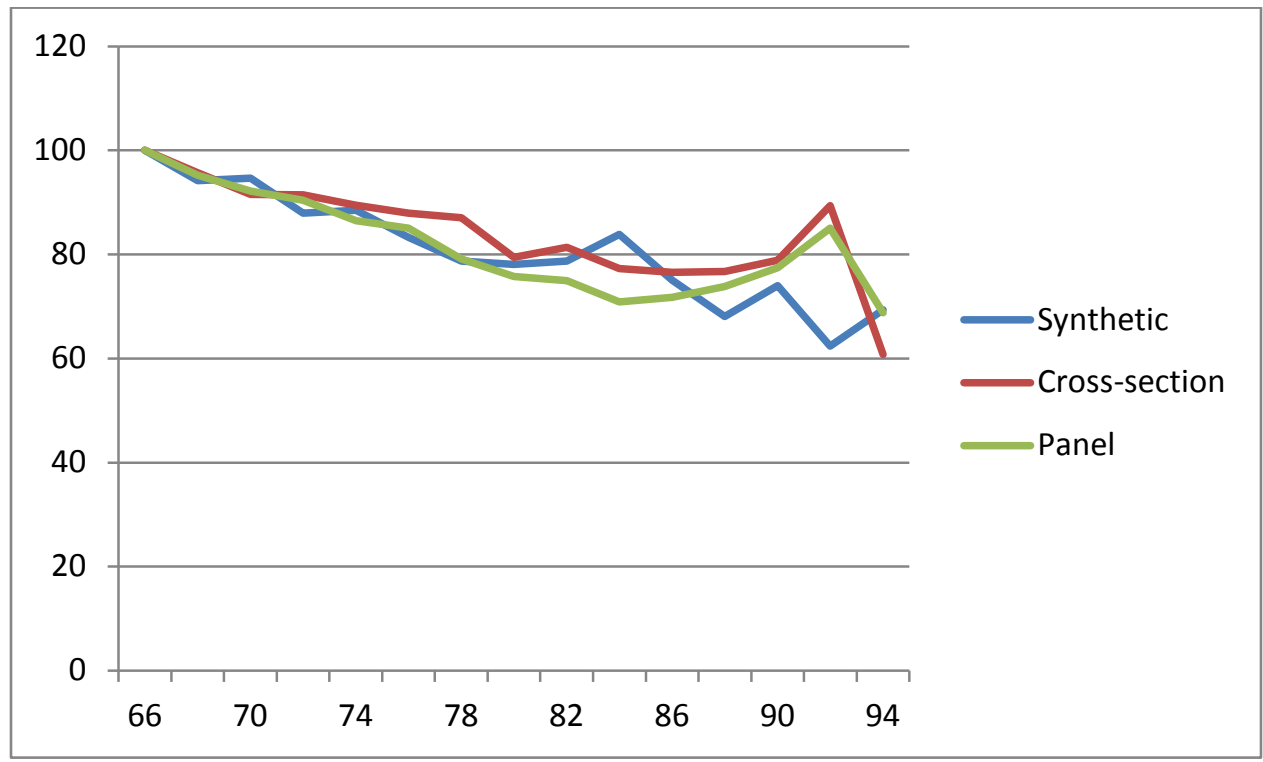


Figure 5 (e) Mean spending paths for singles

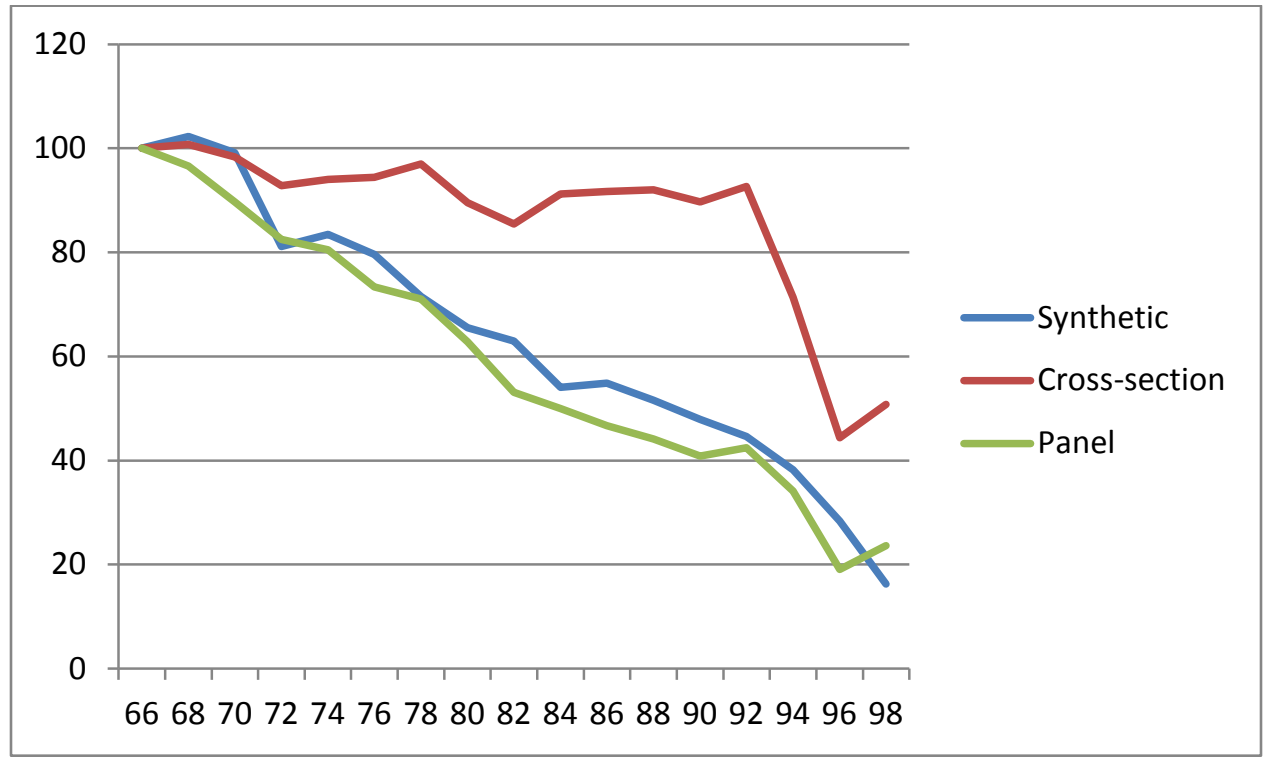

Figure 5 (f) Median spending paths for singles

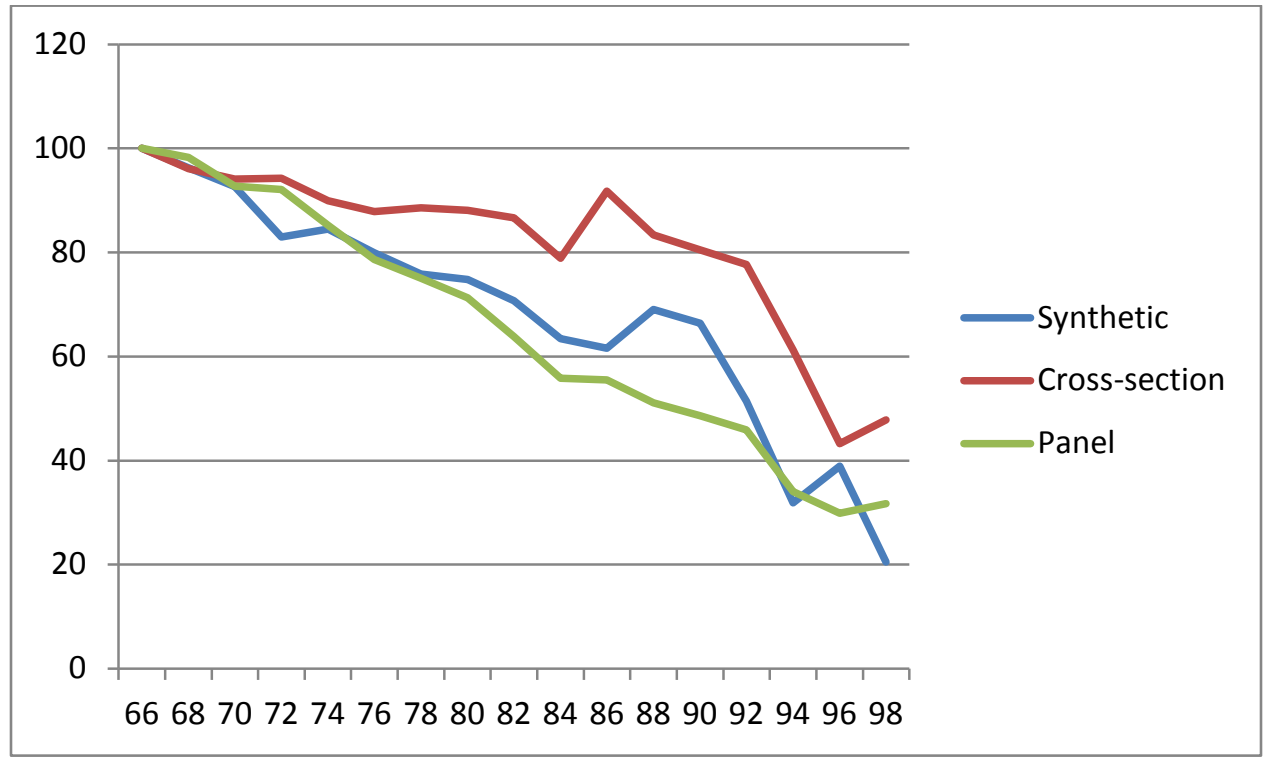

